\title{
Hemoglobin concentration of intestinal parasites infested children in Okada, Edo state, Nigeria
}

\author{
Alfred Friday Ehiaghe, Youtchou Mirabeau Tatfeng, Joy Imuetinya Ehiaghe, Uhuonrenren Osaretin \\ Dapartment of Hematology, Igbinedion University, Okada, Nigeria \\ Email: fredleo2547@yahoo.com, Youtchou@yahoo.com, Ehiaghejoy@yahoo.com, pasito_01@yahoo.com
}

Received 16 July 2013; revised 16 August 2013; accepted 23 August 2013

Copyright (c) 2013 Alfred Friday Ehiaghe et al. This is an open access article distributed under the Creative Commons Attribution License, which permits unrestricted use, distribution, and reproduction in any medium, provided the original work is properly cited.

\begin{abstract}
Anemia in children is defined by the World Health Organization as a hemoglobin concentration below $11 \mathrm{~g} / \mathrm{dl}$ for children (0.5 - $5.0 \mathrm{yrs})$ and $12 \mathrm{~g} / \mathrm{dl}$ for teens (12 - $15 \mathrm{yrs}) .4 \mathrm{ml}$ of venous blood sample was collected in EDTA container. Of the total of three hundred and thirty four (334) subjects, one hundred and fifty two (152) were Females and one hundred and eighty two (182) were Males. Intestinal parasite assessment was done by Direct Smear technique and Formol-Ether concentration methods. Hemoglobin concentration was analyzed using Cyanmethaemoglobin method. Thirty (30) subjects were infested with Ascaris lumbricoides (single infestation), Ninety Five (95) subjects were infested with Ascaris lumbricoides and Hookworm (Double infestation) and Forty Two (42) subjects were infested with Ascaris lumbricoides, Hookworm, Entamoeba histolytica and Trichuris trichiura (Multiple infestation). The Mean \pm Standard Deviation of Hemoglobin concentration of the various infestation types against the control subject shows a statistically significant decrease $(P<$ 0.05). Our data confirm that intestinal parasites are associated with anemia irrespective of gender and age in children.
\end{abstract}

Keywords: Anemia; Hemoglobin Concentration;

Ascaris lumbricoides; Hookworm; Cyanmethaemoglobin Method

\section{INTRODUCTION}

It is estimated globally that about 3.5 billion people are infested with intestinal parasite and that 450 million are ill as a result of these infection, the majority being children [1]. These infestations are regarded as a serious health problem, due to its iron deficiency capability, growth retardation in children and other physical and mental health problems. Parasitosis is a major health problem in Nigeria with 50\% prevalence among urban dwellers and 68\% prevalence among rural population $[2,3]$.

Anemia in children is defined by the World Health Organization as a hemoglobin concentration below 11 $\mathrm{g} / \mathrm{dl}$ for children (0.5 - $5.0 \mathrm{yrs}$ ) and $12 \mathrm{~g} / \mathrm{dl}$ for teens (12 15 yrs) [4]. It can denote decreased oxygen binding ability of each hemoglobin molecule due to deformity or lack in numerical development as in some types of hemoglobin deficiency [5]. Chronic anemia is associated with behavioral disturbance in children as a result of impaired neurological development in infants and reduced scholastic performance in children of school age. Restless legs syndrome is more common in those with iron deficiency anemia, common symptoms include swelling of the legs or arms, chronic heartburn, vague bruises, vomiting, increased sweating, pallor and blood in stool. The most common cause of microcytic anemia is parasitic infestations, while the most common cause of macrocyte anemia is due to deficiency of vitamin $\mathrm{B}_{12}$ or folate either due to inadequate intake or malabsorption from the gastro intestinal tract as a result of intestinal parasitosis [6].

This study is aim at understanding the causes of alterations in Hemoglobin concentration in intestinal parasites infested children.

\section{MATERIALS AND METHODS}

Study Area: The study was carried out in the College of Health Science, Department of Hematology, Igbinedion University, Okada. Ethical approval was obtained from the IUO ethic committee and informed consent from the parents of the children.

Sample Size: The sample size was obtained using this formula [7] 


$$
N=Z^{2} x P(1-P) / d^{2}
$$

where:

$N=$ Minimum sample size

$D=$ desired level of significance (0.05)

$Z=$ Confidence interval (1.96)

$P=$ Prevalence rate (68\%) [3].

Using this formula, the minimum number of sample will be 334 children.

Inclusion criteria: the Inclusion criteria was young children within the age range of 0 - 15 years with no history of any major illness and have not taken a drugs in recent past (2 or 3 weeks before).

Exclusion Criteria: The exclusion criteria were subject above 15 years and a history of an underlying illness.

Duration of Study: This study was carried out between March 2010 to March 2011.

Limitation of the Study: Subject compliance to samples collection was the limitation to this study.

\subsection{Sample Collection and Processing}

The subjects consist of 334 children which comprises of 152 females and 182 males. The subjects were further divided into two groups. Group one consist of 167 children infested with intestinal parasite confirmed to be positive with Direct smear technique and Formol-Ether concentration method described earlier [8], while Group two consist of 167 children apparently healthy control subjects and faecal samples were confirmed to be negative using the Formol-Ether concentration methods.

\subsection{Blood Sample Processing}

Sample Preparation and test performance for Hemoglobin concentrations were done using the Cyanmethemoglobin method described by [9]. 20 Microliter of blood was diluted in a $5 \mathrm{ml}$ buffered solution of Potassium Cyanide to yield the stable hemoglobin derivative cyanmethemoglobin. The Potassium Ferricyanide converts the Hemoglobin to Methemoglobin by the action of Potassium Cyanide. This must be allowed to stand for at least three minutes, to allow for complete conversion of Hemoglobin to Cyanmethemoglobin, before the absorbance is measured against a reagents blank at a wavelength of $540 \mathrm{~mm}$ using a Spectrophotometer.

\subsection{Statistical Analysis}

Data were collected using self administered semi-structured questionnaire. All numerical results were collated from the groups. Data were presented as mean \pm standard deviation (S.D) and analyzed using one way analysis of variance (ANOVA) Using SPSS version 18.0, P $<0.05$ were considered significant.

\section{RESULTS}

Table 1: shows that of Three Hundred and Thirty (334) subjects, One Hundred and Fifty Two (152) were Females and One Hundred and Eighty Two (182) were Males.

Table 2: shows that Thirty (30) subjects were infested with Ascaris lumbricoides (single infestation),Ninety Five (95) subjects were infested with Ascaris lumbricoides and Hookworm (Double infestation) and Forty Two (42) subjects were infested with Ascaris lumbricoides, Hookworm, Entamoeba histolytica and Trichuris trichiura (Multiple infestation).

Table 3: shows the Mean \pm Standard Deviation of Hemoglobin concentration of the various infestation types against the control subject shows a statistically significant decrease $(\mathrm{P}<0.05)$.

$\mathrm{S}=$ Statistically significant decrease as compared with the control using Tukey-Kramer multiple comparisons test using SPSS 18.0 (Statistical packages for social Scientist-version 18.0) Statistical program. P values $<0.05$ will be considered significant.

Table 1. Showing age and sex distribution of subjects.

\begin{tabular}{cccccc}
\hline $\begin{array}{c}\text { Age Range } \\
\text { (yrs) }\end{array}$ & Subjects & Females & $\begin{array}{c}\text { Infested } \\
\text { Female (\%) }\end{array}$ & Males & $\begin{array}{c}\text { Infested } \\
\text { Males (\%) }\end{array}$ \\
\hline $0-5$ & 54 & 22 & $8(36.4)$ & 32 & $9(28.1)$ \\
$6-10$ & 105 & 50 & $20(40)$ & 55 & $25(45.5)$ \\
$11-15$ & 175 & 80 & $50(62.5)$ & 95 & $55(58.0)$ \\
Total & 334 & 152 & $78(51)$ & 182 & $89(49)$ \\
\hline
\end{tabular}

Table 2. Showing infestation types and parasites isolated from infested subjects.

\begin{tabular}{ccc}
\hline Infestation Type & $\begin{array}{c}\text { Parasite } \\
\text { Isolated }\end{array}$ & $\begin{array}{c}\text { Infected } \\
\text { Subjects }\end{array}$ \\
\hline Single & A.l. & 30 \\
Double & A.l/H.w. & 95 \\
Multiple & $\begin{array}{c}\text { A.l., H.w., } \\
\text { E.h AND T.t }\end{array}$ & 42 \\
\hline
\end{tabular}

Keys: A.l. = Ascaris lumbricoides, H.w. = Hookworm, E.h = Entamoeba histolytica, T.t $=$ Trichuris trichiura .

Table 3. Showing the mean \pm standard deviation of infected subjects and control subjects with their P values.

\begin{tabular}{ccccc}
\hline \multicolumn{5}{c}{$\begin{array}{c}\text { Infestation } \\
\text { Type }\end{array}$} \\
\hline Parameter & Single & Double & Multiple & Control $\quad$ P Values \\
\hline $\begin{array}{c}\text { HB Conc. } \\
\text { (mg/dl) }\end{array}$ & $10.0 \pm 0.01^{\mathrm{s}}$ & $9.6 \pm 0.03^{\mathrm{s}}$ & $9.4 \pm 0.02^{\mathrm{s}}$ & $16 \pm 0.02 \quad \mathrm{P}<0.05$ \\
\hline
\end{tabular}




\section{DISCUSSION}

We observed that $50 \%$ of the populations of anemic children in Okada were infested with intestinal parasite. These could be attributed to the increased incidence of intestinal parasitic infestation among children because of their unhygienic feed habit and low level of education. These have been reported by these authors. The high rate of intestinal parasitic infestation among children is attributed to defecation practices of young children and outdoor feeding in higher age group [10]. Children especially in rural areas have high rates of intestinal parasite infestation due to poor sanitation, contact with contaminated water supply, low level of education and malnutrition $[11,12]$.

We observed a decreased in the hemoglobin concentration of children infested with intestinal parasite from single to multiple infestations as compared with the control $(\mathrm{P}<0.05)$. These may be due to the number of intestinal parasite present in the intestine, the metabolic process of the parasite reduction of the immune response as a result of malnutrition or change in the life style of the infested person. These have been reported by other researchers. The association between low hemoglobin and parasite positivity seems possible because intestinal parasites are lodged in the duodenum and jejunum, the site of iron absorption [13]. Hookworm infestation is known to result in anemia due to chronic blood loss [14-16]. The relationship between parasite infestation and anemia is a pathogenic-physiologic type [12]. It is recognized that certain factors play an important role. They include the strain and number of the parasite, the size and site, metabolic process of the parasite, particularly the nature of waste products, age and level of immunity at the time of infestation or presence of co-existing condition which reduce immune responses, malnutrition and the life style of the person infested [13]. Anemia caused by parasitic infestation with nutritional undertone is due to a deficiency of iron, folic acid, B-complex and protein [14]. Mucosal changes have been reported in subjects infested with intestinal parasites infestation [17]. Gastric juices that facilitate iron absorption have been found to be reduced in Ascariasis [18]. Shortened gut transit time and steatorrhea which accompanies intestinal infestation can potentially reduce iron absorption from the gut [13].

\section{CONCLUSION}

In this study, $50 \%$ of the children in Okada were found to be intestinal parasite infested and anemic. Urgent remedial steps are needed on community basis to improve the nutritional status and control parasitic infestation.

\section{REFERENCES}

[1] World Health Organization (1998) Control of tropical disease. WHO, Geneva.

[2] Evans, A.C. and Stehenson, L.S. (1995) Not by drugs alone: The fight against parasitic helminthus. World Health Forum, 16, 258-261.

[3] Arinola, O.G., Yagub, A. and Rahamon, K.S. (2012) Reduced serum IgE level in Nigerian Children with helminthiasis compared with protozoan infection: Implication on hygine hypothesis. Annals of Biological Research, 3, 5754-5757.

[4] World Health Organization (2008) World wide prevalence of anaemia 1993-2005. World Health Organization, Geneva.

[5] Saimak, T.N. (2009) MD, MPH. Editor Melissa Conrad Stoppler MD.

[6] Rasmuussen, S.A., Fernhoff, P.M. and Scanlon, K.S. (2001) Vitamin $\mathrm{B}_{12}$ deficiency in children and adolescents. Journal of Pediatrics, 138, 10-17. http://dx.doi.org/10.1067/mpd.2001.112160

[7] Naing, L., Winn, T. and Rush, B.N. (2006) Practical issues in calculating the sample size for prevalence studies. Archives of Orofacial Sciences, 1, 9-14.

[8] Monica, C. (2000) District laboratory practice in tropical countries Part 2. Cambridge Low Price Editions, Cambridge University Press, 207-212 and 253-266.

[9] Dacis, J. and Lewis, D. (2006) Practical hematology. 8th Edition, Churchill Livingstone, London, 27-30.

[10] Shammari, S.A., Khoja, T., Khwasky, F.E. and Gad, A. (2001) Intestinal parasitic disease in Riyadh, Saudi Arabia. Prevalence, sociodemographic and environmental associates. Tropical Medicine \& International Health, 6, 184-189.

http://dx.doi.org/10.1046/j.1365-3156.2001.00698.x

[11] Arinola, O.G. and Fawole, O.O. (1995) Prevalence of protozoan and heliminthic infections among different occupational and age group in Iroko Village, Oyo State, Nigeria. Journal of Engineering Science and Technology, 2, 51-57.

[12] Ramesh, G.N., Malla, N., Raju, G.S., Sehgal, R., Ganguly, N.K., Mahajan, R.C. and Dilawari, J.B. (1991) Epidemiological study of parasitic infestations in lower socioeconomic group in chandigarh (North Indian). Indian Journal of Medical Research, 93, 47-50.

[13] Rarness, L.A. (1992) Nutrition and nutritional disorders. In: Behrman, R.E., Kliegman, R.M., Nelson, W.E. and Vaughan, V.C., Eds., Nelson's Testbook of Pediatrics, 14th Edition, W.B. Saunders Co., Philadelphia, 105-146.

[14] World Health Organization (1978) Expert committee. Public health significance of Intestinal parasite infestation Bill. WHO, 65, 575-588.

[15] Kazora, J.W. and Mahm, A.A.F. (1992) Intestinal nematodes. In: Behrman, R.E., Kliegman, R.M., Nelson, W.E. and Vaughan, V.C., Eds., Nelson's Testbook of Pediatrics, 14th Edition, W.B. Saunders Co., Philadelphia, 896-899.

[16] Warren, K.S., Dindy, D.A.P., Anderson, R.M., Davis, A.R., Henderson, D.A. and Jamison, D.T. (1993) Helminthic infections. In: Jamison, D.T., Mosley, W.H., Measham, A.R. and Bobadilla, J.L., Eds., Disease control 
priorities in developing countries, University Press, New York, Oxford, 131-160.

[17] Slata, R.A. and Aucott, J.N. (1992) Parasitic infection. In: Behrman, R.E., Khegman, L.M., Nelson, W.E. and Vaughan, V.C., Eds., Nelson's Testbook of Pediatrics, 14th
Edition, W.B. Saunders Co., Philadelphia, 872-876.

[18] Blumenthal, D. and Scheltz, M.G. (1976) Effect of ascaris infection on nutritional status in children. The American Journal of Tropical Medicine and Hygiene, 25, 682-690. 